\title{
STUDIO DE UNA PEQUEÑA Y DESCONOCIDA COLECCIÓN: LOS KYÔDO-GANGU DE JOAN MIRÓ
}

MURIEL GÓMEZ PRADAS**

Departamento de Artes y Humanidades. Universitat Oberta de Catalunya mgomezpr@uoc.edu

\begin{abstract}
Resumen: En este artículo abordamos el estudio de unos singulares objetos japoneses que Joan Miró atesoró tanto en su taller como en su residencia mallorquina. Se trata de unos kyôdo-gangu o juguetes tradicionales y populares japoneses, unos objetos de pequeño tamaño, que tanto pueden ser figuras antropomorfas como zoomorfas, de materiales sencillos y cotidianos, de carácter tradicional y de consumo popular y que solían tener usos y significados muy variados. El objetivo de este artículo es trazar la biografía de estos objetos, analizando su simbología, procedencia y uso social, e intentando establecer cómo llegaron a manos del artista.
\end{abstract}

Palabras clave: kyôdo-gangu / Joan Miró / Japón / coleccionismo / uso social.

\section{STUDY OF A SMALL AND UNKNOWN COLLECTION: JOAN MIRÓ'S KYÔDO-GANGU}

Abstract: This article is focused on the analysis of some singular Japanese objects that Joan Miró treasured, both in his workshop and in his Majorcan residence. These singular objects are kyôdo-gangu or Japanese Folk Toys, which can be either anthropomorphic or zoomorphic figures. They are made of simple and everyday materials, of a traditional nature and popular consumption and which used to have diverse meanings and uses. The aim of this article is to trace their biography, by analyzing their symbology, origin and social use, and try to determine how they arrived to the artist's hands.

Key words: kyôdo-gangu / Joan Miró / Japan / collecting / social use.

\section{Introducción}

Entre todos los objetos que Joan Miró (1893-1983) tenía y coleccionaba, tanto en el taller diseñado por Sert en Mallorca como en su casa, llaman la atención unos pequeños kyôdo-gangu o juguetes tradicionales y populares japoneses. El objetivo de este artículo es trazar la biografía ${ }^{1}$ de estos objetos fijándonos en el camino que han seguido: desde ser portadores de buena suerte y esperanza para aquel que los recibía, en el contexto de un entramado simbólico que se materializaba en estas figuras de pequeñas dimensiones, hasta devenir objetos de coleccionismo o souvenirs. Es en este proceso de transición y cambio de sus usos cotidianos, en

\footnotetext{
* Fecha de recepción: 15 de abril de 2019 / Fecha de aceptación: 7 de octubre de 2019.

** Este artículo recoge los resultados de la investigación llevada a cabo en el marco del Proyecto de I+D: "Protagonistas de la presencia e impacto del arte japonés en España" (HAR 2014-55851-P), financiado por el Ministerio de Economía y Competitividad, así como parte del trabajo llevado a cabo en mi tesis doctoral (2011). Quiero dejar constancia de mi más sincero agradecimiento por toda su ayuda y disponibilidad, a Joan Punyet Miró y Lola Fernández.
}

Abreviaturas: FPJM: Fundació Pilar i Joan Miró, Palma de Mallorca. SM: Successió Miró, Palma de Mallorca. AHCOAC: Arxiu Històric del Colllegi d'Arquitectes de Catalunya, Barcelona. ANC: Arxiu Nacional de Catalunya, Sant Cugat del Vallès, Barcelona. 1 APPADURAl, A. (ed.), 1986, pp. 64-68. 
uno de estos caminos, que estos kyôdo-gangu que nos ocupan llegaron a manos de Joan Miró.

Tal y como se destaca en el catálogo de la exposición Miró y el objeto, el artista ya desde joven coleccionó objetos muy diversos, normalmente de procedencia cotidiana y ordinaria como podían ser piedras, juguetes, figuras diversas (entre las que destacan, por ejemplo, los siurells $s^{2}$ mallorquines), herramientas de cocina, etc. ${ }^{3}$ Su interés por los juguetes y el arte infantil viene de lejos, y ha sido un elemento recurrente en las vanguardias de principios del siglo XX. ${ }^{4}$ Como recoge William Jeffet, en el París de los años 30, "todo el mundo hablaba de juguetes, y L'intransigeant le dedicó dos artículos". ${ }^{5}$ Y en la Barcelona de la misma década, el grupo de vanguardia A.D.L.A.N., ${ }^{6}$ realizó una exposición de siurells mallorquines (enero 1933) y de dibujos infantiles (mayo 1935). ${ }^{7}$ Y precisamente también en este periodo es cuando Miró elabora sus "pinturas-objetos", ensamblajes de objetos encontrados decorados, o cuando empieza a utilizar materiales inusuales como soporte. ${ }^{8}$

Además de su interés por los juguetes, hemos de añadir su especial interés por Japón, ya desde los inicios de su carrera. Queda fuera del foco del artículo, pero tan solo recordar su temprano interés por el Japonismo, -tal y como se refleja en la obra de 1917, Retrato de Enric Cristòfol-, ${ }^{9}$ su paso por París, su amistad con Tsuguharu (Léonard) Foujita (1886-1968), el interés de amigos cercanos, como Bretón y Masson, por el arte de Asia oriental, etc.

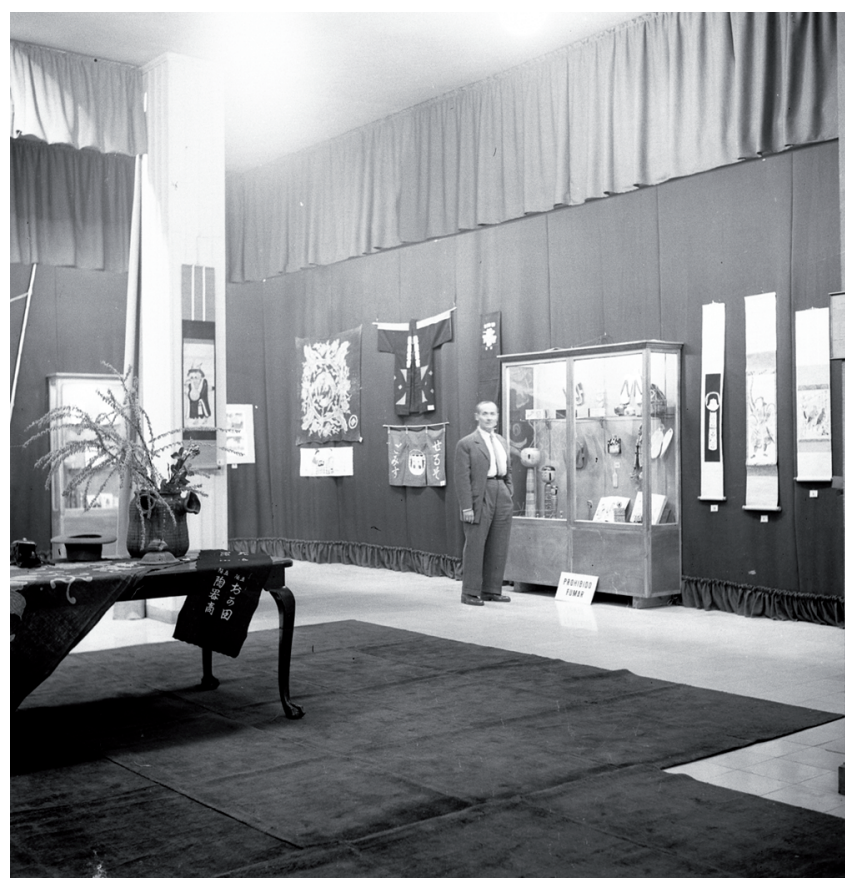

Fig. 1. Visita de Joan Miró a la "Exposición de arte popular japonés" en el Reial Cercle Artístic de Barcelona, 1950. Fotografía Joaquim Gomis, Arxiu Nacional de Catalunya. (C) Herederos de Joaquim Gomis, Fundació Joan Miró, Barcelona.

Ya en nuestro país, y relacionado con la temática que nos ocupa, es importante destacar que existe constancia documental y gráfica que muestra como

${ }^{2}$ El siurell es una figura-silbato de arcilla modelada mano, blanqueada con cal y decorada con pinceladas de colores (verde, rojo). Actualmente es un icono turístico de Mallorca, pero en relación a sus orígenes hay teorías diversas, ya que hay estudiosos que los relacionan con la tradición árabe, mientras que otros apuntan la cerámica minoica cretense. Joan Miró era un gran aficionado a coleccionar estas figuras tradicionales mallorquinas.

3 JEFFET, W., 2015, p. 15.

${ }^{4}$ Véase por ejemplo el artículo de GREEN, C. "The Infant in the Adult. Joan Miró and the Infantile Image". En: Fineberg, J. (ed). Discovering Child Art. Essais on Childhood, Primitivism and Modernism. Princeton: Princeton University Pres, 2001, pp. 210234 así como el catálogo de GUIGON, E. (ed). La infancia del arte. Arte de los niños y arte moderno en España.Teruel: Museo de Teruel, 1996.

5 JEFFET, W., 2015, p. 20.

${ }^{6}$ La asociación A.D.L.A.N. (Amics De L'Art Nou [Amigos del Arte Nuevo]) fue, hasta el estallido de la guerra civil, la promotora de toda una serie de actividades artísticas de vanguardia en Barcelona (1932-1936). Sus máximos impulsores fueron Joan Prats, Josep Lluís Sert y Joaquim Gomis. Para información detallada sobre ADLAN véase el monográfico de la revista AC publicado con motivo de la exposición de 1970 en Barcelona, Cuadernos de arquitectura: ADLAN, testimonio de una época. BarceIona, 1970, n 79 así como las publicaciones de: CORREDOR-MATHEOS, J. "ADLAN i el Surrealisme". En: Surrealisme a Catalunya 1924-1936. De l'Amics de les Arts al Logicofobisme. Barcelona: Polígrafa, 1988, pp. 49-52; CORREDOR-MATHEOS, J. et al. Las vanguardias en Cataluña 1906-1939. Barcelona: Fundació Caixa de Catalunya, 1992; y SUBIRANA, R.M. "ADLAN and the artists of Republic". En: Raeburn, M. (ed). Homage to Barcelona. The City and its Art 1888-1936. Londres: The Arts Council of Great Britain, 1985, pp. 211-225.

7 Según consta en el documento con la programación de ADLAN de 1932 a 1935 conservada en el Fons ADLAN, Arxiu Històric del Collegi d'Arquitectes de Catalunya (AHCOAC, Barcelona). Documento mecanografiado con añadidos a lápiz.

8 JEFFET, W., 2015, p. 25.

9 Recordar que ya en una obra de Miró de 1917, concretamente Retrato de Enric Cristòfol Ricart (actualmente en el MoMA, número de registro 822.1996), aparece una estampa ukiyo-e japonesa de finales del siglo XIX. 
Joan Miró visitó la exposición titulada Exposición de arte popular japonés que tuvo lugar en el Reial Cercle Artístic de Barcelona en 1950. Esta exposición, organizada por el grupo Cobalto 49, ${ }^{10}$ reunía obras de la colección de Cels Gomis y Eudald Serra, recién llegados ambos de su época de residencia en Japón. ${ }^{11}$ También se exponían algunos objetos que el propio Serra había donado al Museo Etnológico y Colonial de Barcelona, así como una selección de dibujos infantiles de la colección de Ángel Ferrant, miembro destacado de A.D.L.A.N. y maestro de Serra. Las crónicas del momento resaltaban que "Los tres se han conjurado para ofrecer a Barcelona una visión densa, pero sintetizada, esquematizada, del arte popular nipón. Se trata de exaltar los objetos humildes, modestos, pero graciosos, elegantes y cautivadores dentro de la simplicidad de su armonía". ${ }^{2}$ Un tipo de objetos, como vemos, en total consonancia con los intereses de Miró por objetos cotidianos, simples y sencillos, por su aprecio en el juego de texturas. Aspectos todos ellos que concuerdan también con las ideas del Mingei Undo, ${ }^{13}$ que podríamos sintetizar como una filosofía idealizada de la producción artesanal cuyo principal ideólogo fue Yanagi Soetsu (1889-1961). ${ }^{14}$ Para que un objeto fuera considerado como verdaderamente mingei, tenía que cumplir una serie de requisitos según el ideario propuesto por Yanagi, como que tenían que ser funcionales -ya que de su funcionalidad deriva su belleza-, ${ }^{15}$ comunes y cotidianos -utilizados por la gente común diariamente-, hechos a mano, anónimos y realizados con materiales naturales.

De hecho, el propio Miró tenía en su biblioteca personal ${ }^{16}$ un ejemplar del libro de Yanagi Soetsu, El arte popular japonés, ${ }^{17}$ publicado Japón en 1939 en castellano, y que bien podría haber sido un regalo de Serra o Gomis, ya que ambos tenían ejemplares de este libro en sus bibliotecas personales. Así por ejemplo, el interés de Eudald Serra por el libro es evidente, ya que en su biblioteca particular constaba la existencia de cinco ejemplares de dicho libro. ${ }^{18}$ Y se sabe además que el ejemplar existente en la biblioteca del Museu Etnològic de Barcelona fue donación suya.

Retomando la visita a la exposición celebrada en Barcelona en 1950, sabemos de ella gracias a las crónicas del momento, especialmente a la de la revista Destino, ${ }^{19}$ así como las fotografías realizadas por Joaquim Gomis, -hermano de Cels y uno

${ }^{10}$ Club Cobalto, Cobalto 49 o Club 49 fue una agrupación que surge en la Barcelona de 1949 con la intención de dar a conocer las nuevas manifestaciones artísticas del momento con la organización de exposiciones, conciertos, conferencias y el impulso de la revista Cobalto 49, de la cual salieron cuatro números. Sus impulsores fueron Joan Prats, Sebatià Gasch, Joaquim Gomis, Sixte Illescas y Eudald Serra (procedentes de ADLAN), y María Teresa Bermejo y R. Santos Torroella (de la revista de arte Cobalto, que dio nombre al grupo). Para información detallada del grupo y sus actividades véase BONET, P.; PERAN, M. Club 49. Reobrir el joc, 1949-1971. Barcelona: Generalitat de Catalunya, 2000.

${ }^{11}$ Aunque escapa del foco del artículo, para información sobre este periodo en la trayectoria vital y artística de Eudald Serra véase los artículos de GÓMEZ PRADAS, M. "The Mingei Undô, Eudald Serra and the Japanese Folk Craft Collections of the Ethnology Museum of Barcelona: the Provenance of a Collection", Museum History Journal, 2018 (https://doi.org/10.1080/ 19369816.2018.1526453), GÓMEZ PRADAS, M. "A.D.L.A.N y la promoción de jóvenes artistas: Ramón Marinel·lo, Jaume Sans y Eudald Serra". Arte, Individuo y Sociedad, 30(2) 2018, pp. 225-242 y GÓMEZ PRADAS, M. "La mirada de Eudald Serra. El artista a través de las colecciones de cerámica japonesa del Museo Etnológico de Barcelona". Archivo Español de Arte. LXXXVI/343, 2013, pp. 221-235. Para información sobre Cels Gomis véase BRU, R., 2017, pp. 164-181.

12 "Japón en la Plaza Catalunya", 1950, p. 7.

${ }^{13}$ El Mingei Undo se suele traducir al inglés como Japanese Folk Craft Movement. Para ahondar en este movimiento estético y filosófico japonés hay numerosa literatura entre la que destacaría BRANDT, K. Kingdom of beauty: Mingei and the politics of folk art in Imperial Japan. Durham: Duke University Press, 2007 y KIKUCHI, Y. Japanese Modernisation and Mingei Theory: Cultural Nationalism and Oriental Orientalis. New York: Routledge Curzon, 2004.

14 Para una biografía completa de Yanagi Soetsu véase el artículo de UTSUMI, T. "Mingei and the Life of Soetsu Yanagi". En Mingei. Two Centuries of Japanese Folk Art. Tokyo: The Japan Folk Arts Museum, 1995, pp. 14-31.

${ }^{15}$ El mismo Yanagi lo resume perfectamente en una sola frase al decir que lo esencial "es la belleza nacida del uso", YANAGI 1989 [1972], p. 197.

${ }^{16}$ Actualmente se conserva en la Fundació Joan Miró de Barcelona.

17 YANAGI, S. El arte popular japonés. Tokyo: Kokusai Bunka Shinkokai, 1939. Traducción de Gonzalo Ariza a partir de la versión inglesa publicada en 1936 de una conferencia que Yanagi Soetsu impartió el 8 de abril de 1936 en el Peers'Club de Tokyo.

18 He de agradecer a la familia el acceso al listado de los libros de la biblioteca personal de Eudald Serra.

19 "Ante muchos de tales objetos, recipientes hogareños de alfarería, utensilios domésticos de loza, los visitantes comentaban 'pero si parece un Miró'. Sí, Juan [sic] Miró también estuvo allí en el día de la inauguración y sintiéndose a sus anchas. Se encontró a si mismo frente a la gracia, diríase perfumada, de aquella sugerente cacharrería". "Japón en la plaza de Cataluña" 1950, p. 7. 
de los fundadores de A.D.L.A.N y Club Cobaltoen las que se ve a Miró tanto en la entrada como en el interior de la exposición. ${ }^{20}$

Por ello, por este afán coleccionista de objetos sencillos y cotidianos, junto con su demostrado interés por la cultura japonesa, no extraña que Miró, tanto en su taller de Mallorca como en su residencia, atesorara estos objetos japoneses. Pero, ia qué nos estamos refiriendo con el término kyôdogangu? A partir de la década de 1920 se empieza a utilizar el término "kyôdo-gangu" para denominar una tipología de arte popular japonés a la vez que empieza a considerarse como objeto de un nuevo ámbito de estudio y conocimiento. ${ }^{21}$ Así, el término kyôdo-gangu ${ }^{22}$ se aplica a un tipo de figuras antropomorfas o zoomorfas, de materiales sencillos y cotidianos (papel maché, arcilla, madera, papel y paja de arroz), de carácter tradicional y de consumo popular y que solían tener usos, significados, simbologías y funciones muy variados, entre los cuales, el juego era solo es uno de ellos. En realidad, estos objetos de artesanía popular japonesa -traducido al inglés con el no muy acertado término Japanese Folk Toys, es decir, "juguetes tradicionales japoneses"-, son mucho más que una simple creación artesanal destinada a un público infantil. Su origen se remonta al periodo Edo (1600-1868) y estos pequeños objetos, realizados con materiales comunes y corrientes, tienen un papel representativo fundamental: a partir de ellos podemos obtener información sobre costumbres y tradiciones populares, así como sobre acontecimientos históricos, leyendas, pautas de comportamiento y concreción del imaginario social.

Estos objetos podían cumplir varias de estas funciones a la vez. Por ello, dentro de los kyodo-gan$g u$, se distinguen entre los que son amuletos $u$ objetos portadores de suerte (engimono, 縁起物), objetos ornamentales (englobados dentro del tér- mino genérico de okimono, 置物, que se aplica a cualquier objeto decorativo), souvenirs o productos locales que se suelen comprar en templos o santuarios (omiyage, 置物, expresión genérica para definir variados objetos que se venden en estos lugares), y los juguetes como tales (omocha, 玩具). Unos objetos sencillos y populares pero que nos permitirán acceder a antiguas costumbres, creencias y leyendas; historias con las que conoceremos la parte más cotidiana, humana y emocional de la cultura tradicional japonesa. Y dentro de esta taxonomía podemos clasificar algunos de los objetos que encontramos tanto en el taller que Josep Lluís Sert construyó en 1956 en Mallorca para Miró como en su propia residencia mallorquina.

\section{Taller Sert}

Hoy en día, el taller forma parte de la Fundació Pilar i Joan Miró de Mallorca, y se muestra al público tal y como lo tenía el artista, como un ejemplo de su entorno creativo. Podemos ver en él telas, pinceles, pinturas, así como su "colección" de objetos de variada procedencia, una miscelánea entre los cuales destacan aquellos procedentes de la cultura popular de diversas partes del mundo, pudiéndose ver desde siurells mallorquines a figuritas de pesebre, pasando por las kachinas de los Hopi. Y es aquí donde encontramos cinco kyôdogangu, en concreto una kisimayama-ningyô, fusedai, tori, ponpachi y tsuchi-ningyô.

Un ejemplar de omiyage o producto local característico son las kisimayama-ningyô (杵島山人形), unas figuras ornitomorfas sobre ruedas representativas de la prefectura de Saga, concretamente de la zona de aguas termales de Takeo (prefectura de Saga, isla de Kyûshû). ${ }^{23}$ Entre las representaciones de estas urracas, conocidas en Japón como kasasagi o kachi-dori, se pueden distinguir dos tipos bien diferenciados (por forma y color):

\footnotetext{
20 Estas fotografías se conservan en el Fons Joaquim Gomis, Arxiu Nacional de Catalunya (ANC). La que mostramos es inédita, pero hay una más conocida, que muestra a Joan Miró y Eudald Serra en la entrada de la exposición -junto a un kokeshi de gran tamaño y dos koi-nobori-, una copia de la cual Joan Miró conservó toda su vida.

21 KAWAGOE, A., 1997, s/p.

22 Una de las dificultades que encontramos al abordar el estudio del juguete tradicional japonés es hallar una terminología adecuada. El origen de los problemas terminológicos en este campo se encuentra en que la riqueza de matices de los términos japoneses originales, con el paso por las diferentes traducciones, primero del japonés original al inglés (la gran mayoría de los estudiosos occidentales de este tema pertenecen al mundo anglosajón) y posteriormente al castellano, se han perdido o desvirtuado. En la bibliografía especializada en cultura popular y tradicional japonesa, suele utilizarse con asiduidad el término kyôdo-gangu (郷土玩具), que suele traducirse en la historiografía anglosajona como "folk toy" (expresión que es siempre relativa al juguete japonés) y en español como "juguete popular japonés". Un término se utilizó para denominar a un conjunto de objetos de carácter popular que a partir de 1923 empezaron a considerarse como un nuevo campo de estudio; este término, por tanto, tenía un carácter más específico y, si se quiere, científico.

23 Para más información véase la web de la Japan National Tourism Organization: http://www.jnto.go.jp/eng/location/regional/saga/takeo_ureshinoonsen.html (fecha de consulta: 21 de noviembre de 2018).
} 
A. Kachikachi-guruma (かちかち車), de mayor tamaño, cuerpo filiforme y alargado, gran cola y con la decoración pintada en color negro.

B. Kiyaatsuguro-guruma (きやあつぐろ車), cuerpo y cola más pequeños, cabeza más destacada y siempre pintados de color rojo.

El ejemplar de la Fundació Pilar i Joan Miró de Palma es del tipo kachikachi-guruma (FPJM-TS-0238). ${ }^{24}$ La particularidad que tienen en común todos los kisimayama-ningyô es que siempre dejan partes de la corteza del árbol visibles, lo cual les da un cierto aire rústico, de conexión con la naturaleza. Además, al ir sobre ruedas, estas curiosas representaciones ornitomorfas no solo eran objeto de recuerdo, sino que también cumplían una función lúdica como juguete infantil.

Una pequeña figurita de barro con la representación de un perro con un pescado en la mano conocida como fuse-dai (FPJM-TS-0239) es otro de los ejemplares de engimono que Miró conservaba en su taller. Este tipo de figuras solían sumar los significados que tenían estos animales por separado: el perro simbolizaba un parto fácil y el besugo era un símbolo de felicidad y prosperidad, por lo tanto este tipo de figuras se utilizaban tradicionalmente como un amuleto de fertilidad que se solía regalar a las novias. En Japón encontramos figuras como estas en materiales diversos, como podían ser el barro o el papel maché, siendo las de este último material las más conocidas y características, concretamente las de la zona de Takamatsu. En esa zona del Japón existía una antigua costumbre según la cual se solía incluir muñecos de papel maché en la dote de la novia para regalarlos a los miembros de la familia o a los niños del vecindario el día de la boda. Cuanto mayor fuera el número de muñecos mejor era la impresión que causaba la novia durante la ceremonia conocida como yomeiri (嫁入り) o "la entrada de la novia a casa del marido". ${ }^{25}$ Dada la importancia de la institución matrimonial en el Japón tradicional, no es de extrañar la abundancia de muñecos que representaban a una pareja o que incluso se llegaran a utilizar como parte de la dote de la novia.

Otro engimono característico es una pequeña figura ornitomorfa relacionada con la representación de los doce animales del zodíaco (jûnishi, 十二支).

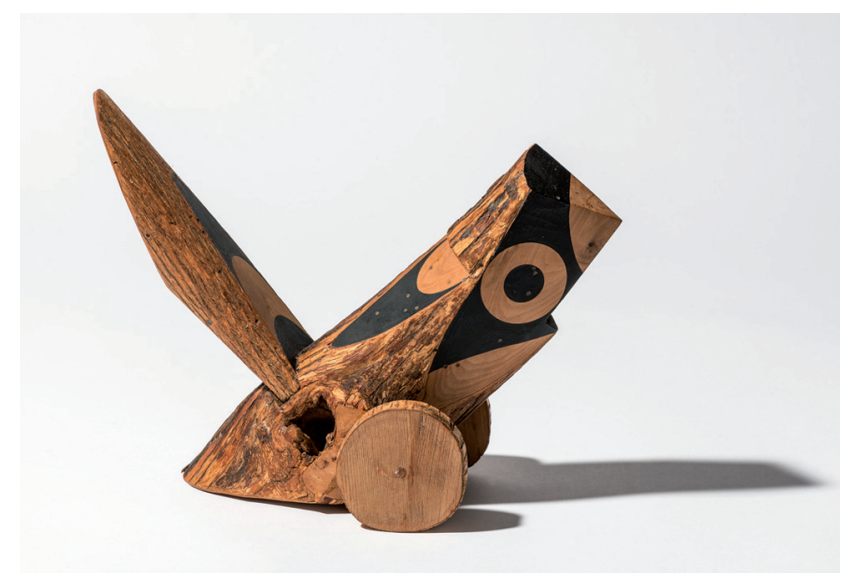

Fig. 2. Kachikachi-guruma. Prefectura de Saga, isla de Kyûshû, Japón. FPJM-TS-0238.

En concreto, la imagen de un gallo (FPJM-TS-0244), que en japonés se denomina tori 西 como animal del jûnishi u ondori 雄鳥 como animal común. Este tipo de representaciones son muy populares en la cultura popular tradicional, ya que los doce animales del zodiaco se utilizaban en China, Corea y Japón para medir el tiempo: los doce animales del zodiaco controlaban los doce meses del año, los días y también las divisiones horarias del día. Con el cambio de año se solían regalar este tipo de figuras correspondientes al año que se iniciaba para ser expuesta en el interior de las casas. $Y$ precisamente 1969, el año del segundo viaje a Japón de Joan Miró, ${ }^{26}$ fue un año del gallo.

Encontramos también un típico ejemplar de Tsuchi-ningyô (土人形) (FPJM-TS-0154), una figura femenina de arcilla, sentada y tocando un instrumento musical de cuerda conocido como samisén (三味線). Figura policromada solo en su parte frontal, con la representación de un sencillo kimono rojo con un par de estilizaciones florales. Es similar a la que se conserva en la Successió Miró, ${ }^{27}$ pero de factura más tosca y sencilla. Estamos ante una representación estereotipada del ideal de belleza femenina. Para representar la esencia de la belleza y de la feminidad tradicional japonesa se tomó como modelo, un prototipo de mujer muy

\footnotetext{
24 Los números y letras se corresponden al número de inventario de la Fundació Pilar i Joan Miró, Mallorca.

25 Véase NISIZAWA, T., 1939, p. 76 y SEKOSO, T., 1973, p. 25. Sobre la tradición de Takamatsu-hariko véase también GÓMEZ PRADAS, M., 2015, pp. 36-43.

26 Para información sobre los viajes de Miró véase CABAÑAS, P., 2000, pp. 21-39.

27 Ver figura $\mathrm{SM} \mathrm{n}{ }^{\circ} 8$.
} 
concreto: la oirán (cortesanas de alto rango) y/o la geisha serán las que representarán el ideal de beIleza y sensualidad femenina. Así, con el surgimiento a mediados del siglo XVII de los Ilamados "barrios de placer" y su aceptación por parte de la sociedad japonesa se puso de manifiesto la existencia de dos mundos femeninos paralelos: el de la esposa -una mujer comprometida con la familia y cuyo principal rol era tener descendencia-, y el de la cortesana y la geisha -una mujer, podríamos decir, especializada en el entretenimiento masculino. En realidad no eran dos mundos excluyentes, sino complementarios: formar una familia y mantenerla unida era un deber social, pero el placer y el amor no pertenecían a él. ${ }^{28}$ Representaciones de esta mujer ideal o soñada las encontramos en las imágenes de las bijin o "mujeres bellas", siendo las más conocidas las de las estampas ukiyo-e del periodo Edo, aunque no las únicas, ya que también hay numerosas representaciones tanto entre los juguetes populares como entre las muñecas tradicionales. ${ }^{29}$

Por último, encontramos un tambor (FPJM-TS0365) que tiene un doble uso: lúdico y protector. Un tambor realizado en papel y bambú con unos brazos móviles ${ }^{30}$ que, al girar el palo sobre su eje, golpean el cuerpo, haciéndolo sonar con un sonido característico similar a "pon pon". De ahí su nombre onomatopéyico: ponpachi (ポンパチ / 初鼓). Como elemento distintivo y característico, en una de las caras encontramos la representación de dos cabezas de caballo, y en la otra un torii o puerta tradicional japonesa -que suele encontrarse en la entrada de los santuarios shintoístas marcando la frontera entre el espacio profano y el sagrado-.

Tambor-amuleto para el primer día del caballo (hatsu-uma 初午祭り), uno de los festivales más im- portantes en el santuario de Kagoshima (prefectura de Kagoshima, isla de Kyûshû). En dicha festividad o matsuri se realiza un desfile con caballos decorados con tambores de papel, así que este juguete-amuleto llamado ponpachi seguía el modelo original que llevaban los caballos.

Los tambores (den-den taiko) son muy característicos de la cultura popular y tradicional japonesa. Y tenían un doble uso, ya que eran uno de los juguetes infantiles más populares, y además también podían tener un plus protector, ya que existía la creencia de que el ruido mantenía alejados a los malos espíritus.

De ninguno de ellos, se conserva documentación de cómo llegaron a manos del artista. ${ }^{31}$ Pero podemos hacer una hipótesis ya que, gracias a las fotos realizadas por Joaquim Gomis a inicios de los años 60 del Taller Sert, ${ }^{32}$ vemos que estos cinco objetos que nos ocupan no aparecen en las estanterías de la entrada, donde actualmente se exponen junto al resto de objetos que sí aparece en las fotografías. Por ello, podríamos deducir que son posteriores a esa fecha. Aspecto que se reafirma si recordamos que posteriormente a la realización de dichas fotografías, concretamente en 1966 y 1969, Miró viajó a Japón. ${ }^{33}$ Por todo ello, bien podrían ser compras o regalos relacionados con dichos viajes. Un hecho que refuerza esta hipótesis es que la presencia de una figura relacionada con los doce animales del zodíaco (jûnishi), en concreto la figura de un gallo, animal representativo del año 1969.

Además de estos cinco pequeños representantes de los kyôdo-gangu que se conservan en su estudio, es interesante resaltar que Joan Miró y Pilar Juncosa convivían en su domicilio con algunos objetos de

28 GÓMEZ PRADAS, M., 2013, pp. 1-19. Hay una cita en el libro de Enrique Gómez Carrillo que, aunque posterior en época (1912), ejemplifica perfectamente esta idea: "las que son nuestras [mujeres], las que viven en nuestra casa, no tienen más misión que la de perpetuar nuestra raza. Son, si usted quiere, las más útiles servidoras del hogar. Pero el placer, la alegría, la voluptuosidad, no anidan jamás bajo el techo conyugal. Son cosas que deben buscarse fuera, y nosotros buscamos en los barrios que se llaman ciudades sin noche". GÓMEZ CARRILLO, E. El Japón heroico y galante. La Coruña: Ediciones del viento, 2009 [1912], p. 31.

29 Así por ejemplo, uno de los tipos más conocidos son las llamadas ukiyo-ningyô, ya que representan figuras o personaje prototípicos del período Edo (1603-1868) siguiendo el ejemplo de los grabados ukiyo-e. Entre los juguetes tradicionales, las más conocidas y populares son las bailarinas y bijin representadas en las figuras de papel maché de Miharu-hariko.

30 Etiqueta ilegible y faltan las semillas (solían ser de soja) que colgaban de los brazos móviles para hacer sonar el tambor.

31 Agradecer toda la ayuda de Pilar Ortega y Gloria Moragues de Successió Miró, así como de Enric Juncosa -restaurador y conservador de la Fundació Pilar i Joan Miró- en el intento de conseguir localizar y trazar el itinerario de estos objetos hasta llegar a manos de Miró

32 En el fondo Joaquim Gomis conservado en el ANC hay una serie de fotografías de detalle del taller, realizadas entre 1960 y 1961.

33 Para información sobre ambos viajes, así como sobre la relación de Miró y Japón, véase el libro de CABAÑAS, P., 2000. Para información detallada del primer viaje a Japón de Joan Miró véase el exhaustivo capítulo de MATSUDA, K., 2015, pp. 362-371. 
tipología similar. De pocos de ellos se guarda documentación sobre cómo llegaron a manos del matrimonio Miró, tal como iremos viendo.

\section{Residencia en Mallorca}

En la Successió Miró actualmente se conservan algunos de los objetos que Miró atesoraba en su domicilio mallorquín. ${ }^{34} \mathrm{Y}$ entre ellos hallamos una de las muñecas más conocidas y representativas del Japón, las kokeshi (こけし), una estilización en madera $^{35}$ torneada de una figura femenina. En la antigua historiografía se había considerado que este tipo de representaciones tenían un claro trasfondo simbólico, bien como amuletos de fecundidad con un claro simbolismo fálico o bien como contenedores del espíritu de las niñas muertas. Hay investigadores como Tekiho Nisizawa ${ }^{36}$ que consideraban que las kokeshi eran una versión modificada de antiguos símbolos fálicos, ya que es bastante común en Japón que imágenes populares o tradicionales tengan este tipo de connotaciones. Además, estas figuras se ofrecían como amuletos a las mujeres que no podían tener hijos. ${ }^{37}$ En cambio, autores como J. Gribbin y L. Baten señalaban otra posibilidad ${ }^{38}$ que residía en la propia etimología: ko significa niño y keshi significa borrar, desaparecer, y se sabe que en años de carestía las mujeres no podían alimentar a todos sus hijos, por lo cual no tenían más opción que el aborto o el infanticidio: así, una recién nacida moría, para que otros niños pudieran continuar viviendo. Las kokeshi se creía que podían ser figuras para contener el espíritu, la esencia de las niñas muertas, y donde poder honrar su recuerdo; de hecho, las kokeshi clásicas son siempre figuras femeninas, y en Japón, al igual que en otros muchos países, las niñas siempre tenían menos oportunidades de sobrevivir que los niños.

En cambio, los últimos estudios de M. Evans y R. Wolf ${ }^{39}$ apuntan a una explicación mucho más simple y sencilla: surge como una muñeca, como un ju- guete, realizadas por los agricultores y leñadores para sus hijas. Con el paso de tiempo esta actividad se transformó en una artesanía propia del lugar (un área famosa y conocida por sus zonas termales u onsen y, por lo tanto, con un gran número de visitantes), que dio paso a una fructífera industria de souvenirs u omigaye en la zona termal.

La realización de las kokeshi dentô o tradicionales no es un trabajo uniforme, sino que existen diez tipologías o familias (kei, 系 $)^{40}$ reconocidas, cada una de ellas con características propias y definitorias. Esta en concreto es una kokeshi tsuchiyu (SM $\mathrm{n}^{\circ}$ 9), ${ }^{41}$ típica de la prefectura de Fukushima (isla de Honshu). El nombre de este tipo de kokeshi tiene localizado su origen en un onsen (zona de aguas termales) situado en la zona montañosa cercana a la ciudad de Fukushima. En concreto, por la inscripción de la base, sabemos que tiene su origen en la zona termal de Sabako.

Las kokeshi tsuchiyu se caracterizan por tener una cabeza relativamente pequeña en comparación con los otros tipos de kokeshi, -los cuales destacan por tener una cabeza de gran tamaño respecto al cuerpo-, y un cuerpo esbelto, que se va afinando de la base a los hombros. Además, se distinguen fácilmente por: ${ }^{42}$

a. el diseño de la cabeza, a base de circulos concéntricos (janome, 蛇の目)

b. la gran expresividad del rostro, en el cual suele destacar una larga nariz del tipo tare-bana (たれ鼻) y ojos del tipo futae-mabuta (二重まぶた) o de "doble párpado".

c. la decoración del delgado cuerpo, también de diseño lineal alrededor de todo el diámetro del cuerpo. Un tipo de decoración realizada con el torno y utilizando colores diversos.

Las kokeshi son de los pocos objetos de artesanía popular y tradicional japonesa que los autores firmaban. Esta en concreto está firmada en la base por Watanabe Kihei (1910-1988), procedente de una

\footnotetext{
${ }^{34}$ Hay que matizar que los objetos que actualmente hay en Successió Miró son solo una parte de los que tenía Joan Miró. Algunos continúan en manos de la familia.

35 La mayor parte de la madera utilizada para realizar las kokeshi es la conocida como mizuki (水木), una variedad de madera de arce caracteriza por su blancura y por ser relativamente dúctil.

${ }^{36}$ Véase NISIZAWA, T., 1939, p. 65.

37 Véase NISIZAWA, T., 1939, p. 65.

38 GRIBBIN, J. \& D., 1984, p. 57; BATEN, L., 1990, p. 43; BATEN, L., 1992, p. 29 y BATEN, L., 2000, p. 55.

39 EVANS, M; WOLF, R., 2005, pp. 12-13.

${ }^{40}$ Diez familias según TAKEUCHI, C., 1982 y EVANS, M;. WOLF, R., 2005, mientras que PATE, A., 2008 considera que son once, ya que diferencia entre Sakunami-kei y Yamagata-kei.

${ }^{41}$ Medidas 23,5 $7 \times 7 \mathrm{~cm}$. Los números y letras se corresponden al número de inventario de la Successió Miró, Mallorca.

42 Según TAKEUCHI, C., 1982, p. 16 y FUNK, S., 2003.
} 
una reconocida familia de artesanos de la tipología de kokeshi tsuchiyu de la zona termal de Sabako. ${ }^{43}$

Sobre esta kokeshi si sabemos su procedencia: fue un regalo de Cels Gomis ${ }^{44}$ a Joan Miró, según consta en la relación realizada por Gomis de su amplia colección de kokeshi. En la transcripción ${ }^{45}$ consultada del inventario de su colección, la catalogada con el número 1210 -comprada en septiembre de 1941 en Sakai por 0.90 yens de la época- fue regalada posteriormente a Joan Miró (aunque no consta cuándo). Además, esta documentación coincide con el hecho que el mismo número de registro, el 1210, aparece escrito en la base de la kokeshi que actualmente se conserva en la Successió Miró. ${ }^{46}$ Podemos colegir por tanto que dicha kokeshi fue un regalo a Joan Miró alrededor de 1950, coincidiendo con el interés mostrado de Miró por la Exposición de Arte popular japonés a la que nos hemos referido con anterioridad.

Otra figura femenina (SM $\mathrm{n}^{\circ}$ 8) que destaca entre los kyôdo-gangu que poseía Miró es una figura de arcilla que representa una mujer vestida con un kimono rojo con decoración floral en blanco y un obi o cinturón de color azul, con una gran lazada en la parte posterior. Presenta un rostro de estilizados y simplificados rasgos físicos en negro (ojos y cejas), y está en actitud de genuflexión y con un abanico (uchiwa) en su mano derecha. Muestra policromía únicamente en la parte delantera. Características todas ellas distintivas de una de las tipologías de figuras de arcilla más conocidas de Japón como son las Hanamaki-ningyô (花巻人形), ${ }^{47}$ prodecentes de Hanamaki (prefectura de Iwate, isla de Honshu). Unas figuras de factura delicada, cuidada y detallada, que destacan además por su gran expresividad y variedad temática, y que se identifican por un colorido brillante y por unas flores distintivas: una flor de cinco pétalos, muy acorde con el propio de nombre de hanamaki (花巻) que viene a significar "envuelto en flores". Otra de las particularidades de estas figuras es que únicamente están pintadas

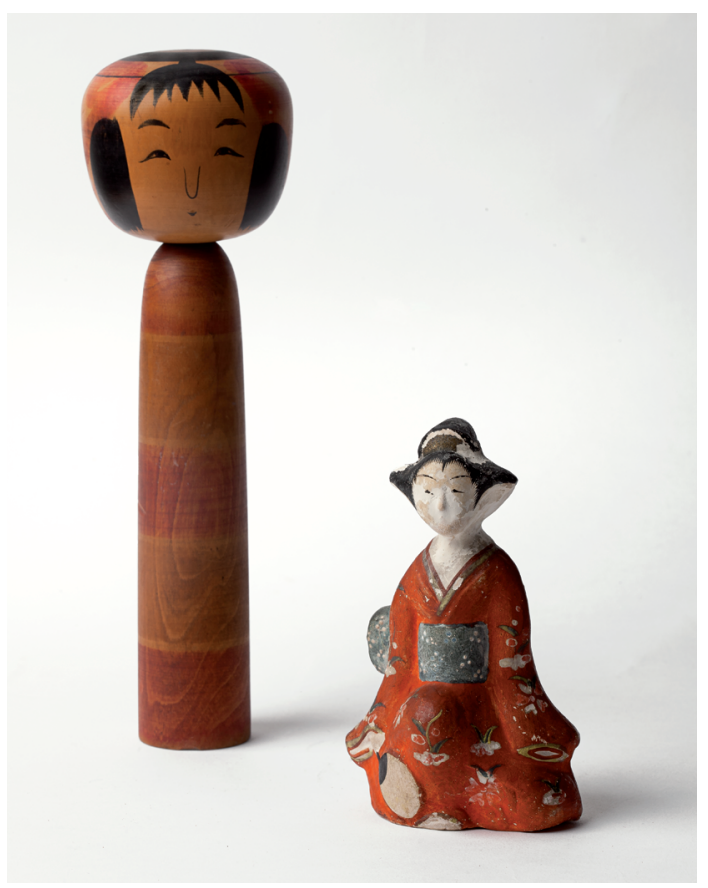

Fig. 3. Kokeshi Tsuchiyu (SM no 9) y Hanamaki-ningyô (SM $n^{\circ}$ 8). Prefectura de Fukushima y prefectura de Iwate respectivamente (isla de Honshu, Japón). Fotografía Gabriel Ramon. Archivo Successió Miró. @ Successió Miró.

por la parte frontal y tienen la base cubierta con una fina lámina de washi o papel japonés.

Esta en concreto podría representar una de las damas de compañía que se exhibían en la festividad del Hina Matsuri o día de las niñas. La festividad del Hina Matsuri, que tiene lugar el 3 de marzo, constituye la celebración del crecimiento de las niñas, aunque antiguamente era un rito primaveral de protección y purificación. Ese día las niñas exponen varias muñecas, siendo las más conocidas las hina-ningyô (㱀人形), que representan al Emperador y la Emperatriz con toda la corte imperial. ${ }^{48} \mathrm{Se}-$

${ }^{43}$ Hijo adoptivo de Watanabe Kin (1881-1941), pintora de kokeshi, y Watanabe Kakuji (1877-1922), maestro tornero de kokeshi. Para más información véase http://kokeshiwiki.com/?p=1789 (fecha de consulta: 9 enero 2019).

${ }^{44}$ Para información sobre Cels Gomis y su estancia en Japón véase el artículo de BRU, R., 2017.

${ }^{45}$ Agradecer a Celso Gomis Müller, hijo de Cels Gomis, la posibilidad de consultar la transcripción realizada en la década de los noventa del inventario de la colección de kokeshi.

${ }^{46}$ He de agradecer a Celso Gomis Müller, su ayuda y colaboración en la identificación de dichos números.

${ }^{47}$ Medidas $13 \times 8,5 \times 6 \mathrm{~cm}$.

${ }^{48}$ Las hina-ningyô (雛人形) son un tipo de muñecas muy apreciadas, que pasan de generación en generación dentro de la familia. Es difícil precisar con exactitud cuándo se inició la costumbre de mostrar muñecas durante esta festividad (véase KAWAKAMI, S., 1995, p. 11), pero sí hay datos para saber que fue durante el período Edo cuando se estableció esta exhibición ya de manera muy similar a como la conocemos hoy en día. En un primer momento la exposición de las hina-ningyô se restringía únicamente a la corte y a las familias de samuráis; y no fue hasta mediados del período Edo que se extendió dicha costumbre entre la burguesía. 
ñalar que las formas y los materiales utilizados en las hina-ningyô se han ido adaptando a los cambios económicos y sociales que ha experimentado Japón tras la revolución Meiji y, por ejemplo, con el tiempo el montaje en ocasiones ha quedado reducido únicamente a la exhibición de la pareja imperial, y se utilizan materiales mucho más sencillos, económicos y populares, como por ejemplo la arcilla.

Siguiendo con los engimono, encontramos una representación de Jizô (地蔵) que es una divinidad budista que suele representarse como un monje con la cabeza afeitada y vestido con un traje sencillo de religioso. Es una figura de gran popularidad en todo Japón, incluso hoy en día. También se le conoce como O-Jizô-sama o Jizô Bosatsu.

Jizo (SM n $\left.{ }^{\circ} 24\right)^{49}$ es el protector de los viajeros, de los bomberos, de las mujeres embarazadas y de los niños (incluyendo tanto a los que aún no han nacido como a aquellos que han muerto prematuramente). Es una divinidad muy popular, con numerosas imágenes situadas tanto en el interior como en el exterior de los templos, y hay diversos tipos y variantes. Una de las tipologías más populares es Mizuko Jizô, el protector de los niños, tanto de los que han de nacer como del espíritu de aquellos que, por circunstancias diversas, han muerto prematuramente (se ha de tener en cuenta que antes del siglo XX la esperanza de vida en Japón era mucho menor que la actual y la posibilidad de que un nino llegase a cumplir los cinco años era de menos del $50 \%$ ). Por ello, incluso actualmente, se pueden ver esculturas de Jizô vestidas con sombreros y baberos, normalmente de color rojo, o acompañadas de juguetes. El significado de esta costumbre tanto puede ser para mostrar la gratitud de los padres por haber curado a su hijo como para pedir ayuda en la salvación del espíritu del hijo fallecido.

De esta tipología hay otro ejemplar, aunque muy diferente. Se trata de una representación de Jizôsama (SM $\left.n^{\circ} 124\right)^{50}$ en piedra policromada. La figura presenta policromía únicamente en la parte frontal, excepto la cabeza totalmente pintada de blanco, y destaca por la túnica roja con mangas

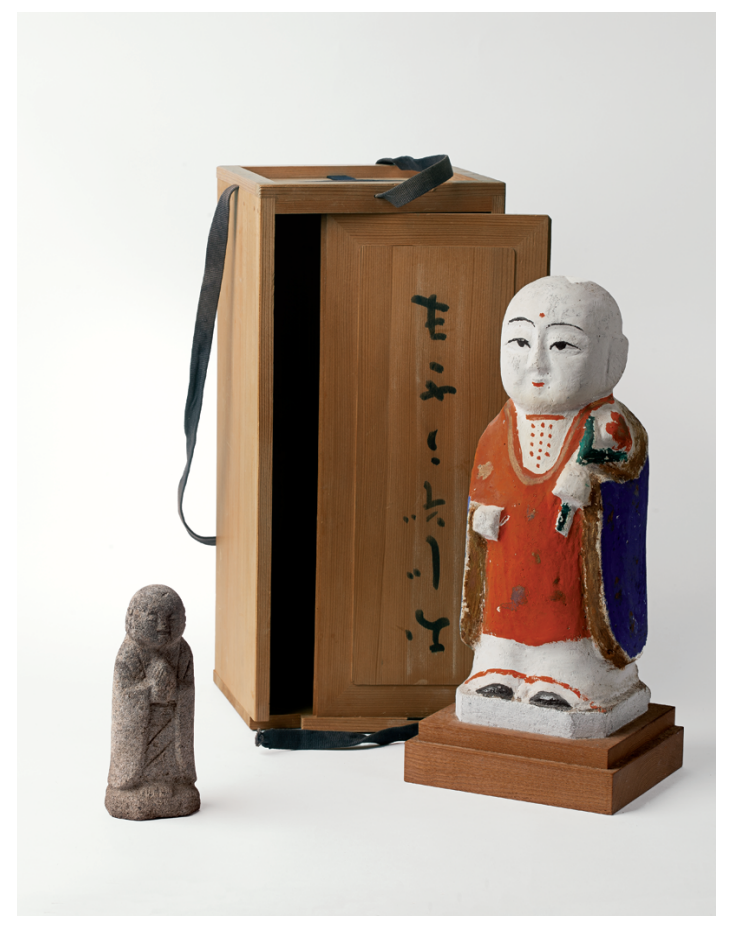

Fig. 4. Jizô (SM no 24) y Jizô-sama (SM no 124). Jizô-sama obra de Tagaki Tatsuo (1932-), Japón. Fotografía Gabriel Ramon. Archivo Successió Miró. @ Successió Miró.

azules y restos de policromía en dorado. Gracias a las inscripciones, tanto de la estela de madera como de la caja de madera original, sabemos que fue un regalo del artista Takagi Tatsuo en septiembre de $1966 .{ }^{51}$ Fecha que concuerda con el año del primer viaje a Japón de Miró, coincidiendo con la exposición antológica en el Museo Nacional de Arte Moderno de Tokio y en el Museo de Arte Moderno de Kioto. ${ }^{52}$ Además, en el archivo de Successió Miró se conserva documentación gráfica de este momento (véase fig. 5).

El autor de esta figura es Tagaki Tatsuo (1932-), pintor, discípulo del pintor Tajima Yasuyoshi y del ceramista Kitaôji Rosanjin. En 1958 recibe del maestro

\footnotetext{
${ }^{49}$ Medidas $16 \times 5,3 \times 6,7 \mathrm{~cm}$. Se desconoce su lugar exacto de procedencia ya que es un tipo de representación muy extendida.

${ }^{50}$ Medidas $33 \times 13 \times 12 \mathrm{~cm}$. La inscripción おじぞうさま de la caja de madera: O-Jizô-sama lo confirma. Agradezco la ayuda en la traducción de la Dra. Yayoi Kawamura (enero de 2018).

51 La inscripción original de la estela es:

一九六六年九月彼岸
}

贈主 高木辰夫

"Año de 1966, Septiembre, Día del equinoccio. Quien regala: Tagaki Tatsuo". He de agradecer a la Dra. Yayoi Kawamura la traducción de dicha inscripción (enero de 2018)

52 Véase MATSUDA, K., 2015, pp. 362-371. 


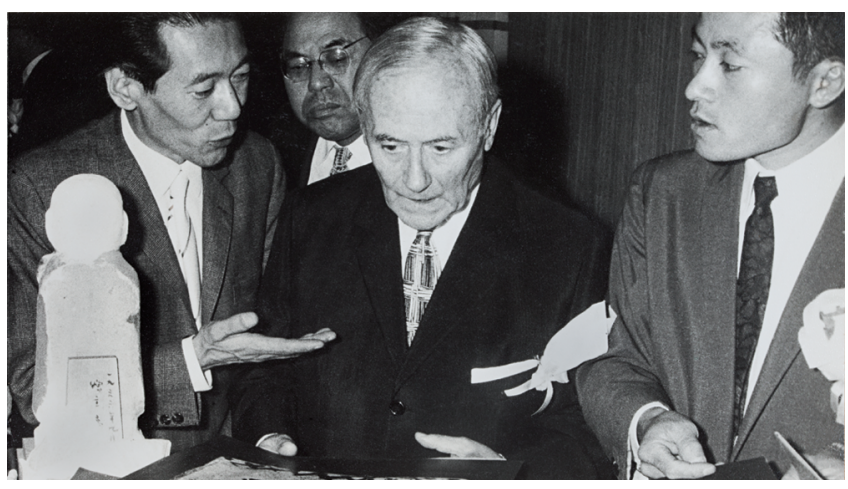

Fig. 5. Fotografía del momento del regalo del Jizô-sama a Joan Miró por parte de su autor, Tagaki Tatsuo. Fotografía Ishikawa Yoshinori. Archivo Successió Miró. @ Successió Miró.

Kitaôji el nombre artístico Ishi dôji, es decir, "Jizô de piedra". De ahí sus características obras con representaciones de Jizô. ${ }^{53}$

Siguiendo con la tipología de los engimono, encontramos un ejemplar de wara-uma (SM n 44), ${ }^{54}$ una estilización de un caballo realizado en paja de arroz. Este ejemplar en concreto ha perdido el jinete (hay un pequeño orificio que muestra dónde se insertaba el jinete), pero conserva la decoración característica como pueden ser los adornos de lacería de tela en rojo y dorado, y la base de brocado color rojo con estilización floral, parte superior de papel con rombo plateado (podría ser la estilización simplificada de un mon o blasón familiar). Los wara-uma se colocaban en el interior de la casa, en los pequenos altares familiares. Esta figura tenía un doble uso: como juguete para los niños y como amuleto o engimono. El wara-uma era un amuleto para proteger a los niños, y que estos crecieran tan fuertes como el guerrero que cabalgaba sobre él. Estos caballos se regalaban a los niños, tras su primer cumpleaños, y por lo tanto el numero de figuritas que el niño recibía era indicativo del círculo familiar de amigos así como del poder económico y la influencia que la familia tenía. ${ }^{55}$

También encontramos ejemplares de uno de los engimono más conocidos y destacados de todo Ja- pón: Daruma (SM n 104), ${ }^{56}$ aunque con una estética muy particular, como veremos. Se ha de tener presente que una de las figuras más destacadas, conocidas y representativas entre los kyodô-gangu es este pequeño tentetieso conocido con el nombre de Daruma (だるま), cuya historia enlaza con la del legendario primer patriarca del budismo zen, Bodhidharma. ${ }^{57}$ Una figura con importantes asociaciones simbólicas, religiosas y rituales y que en la actualidad se presenta en una gran variedad de formas, tamaños, materiales y soportes.

Hay numerosas historias relacionadas con la mítica figura de Bodhidharma, como que vivió en la corte de un emperador en el sur de China, y luego se retiró para meditar. Cuenta la leyenda que permaneció nueve años meditando frente a un muro, a consecuencia de lo cual se le paralizaron las piernas. Otras historias explican que se cortó los párpados para evitar caer en la tentación de cerrar los ojos, de dormirse. Se cuenta también en relación con esta historia que, después de cortarse los párpados, Bodhidharma los tiró al suelo donde enraizaron, dando lugar al arbusto del té (no se ha de olvidar que los monjes budistas bebían té para mantenerse despiertos durante la meditación).

Al margen de si Bodhidharma fue un personaje histórico o mítico, lo cierto es que la forma del Daruma surge directamente de estas leyendas. Los Daruma son tentetiesos (okiagari) que solo tienen cabeza y busto, que están cubiertos por una túnica roja, porque las piernas, tal y como hemos visto, se le habían anquilosado debido a los años de meditación ininterrumpida. Los rasgos faciales no se corresponden con los de los japoneses, ya que muestran un rostro de anchas y pobladas cejas, grandes ojos sin párpados (tal como explica la historia) y bigote.

El Daruma tradicional era una figura con un alto contenido simbólico: cuando se compraba un pequeño Daruma en la entrada del templo, para Año Nuevo, lo que se estaba comprando era esperanza y coraje; los Daruma se han considerado símbolos de felicidad, buena suerte, resistencia, valor y perseverancia, ya que, por mucho que los empujemos siempre vuelven a su posición inicial. Hay un proverbio japonés que dice "siete veces lo

\footnotetext{
${ }^{53}$ Algunas imágenes de sus obras se pueden consultar en: http://kotokobo.main.jp/takagitatuo.html (fecha de consulta: 9 enero 2019).

${ }^{54}$ Medidas $12 \times 2 \times 14,5 \mathrm{~cm}$.

55 SHISHIDO, 1963, p. 62.

56 Medidas $23 \times 13 \times 13 \mathrm{~cm}$. Figura restaurada en 2015 .

57 Para más información sobre la figura de Bodhidharma y Daruma véase R. MOES, R., 1995, pp. 34-35 y MCFARLAND, H. N., 1987.
} 
empujé, ocho se levantó" que caracteriza perfectamente el espíritu indomable que se le atribuye. Además, al estar normalmente pintado o lacado en rojo, evocando el dothi de los monjes hindúes, era considerado como un protector contra las enfermedades según las cualidades profilácticas que se atribuyen en todo Oriente al color rojo.

Al ser un personaje de gran popularidad, en la actualidad se presenta en una gran variedad de formas, tamaños, materiales y soportes. La figura que aquí nos ocupa, no es de papel maché como suele ser característico, sino que tiene el rostro de papel pintado, con dos cuentas negras a modo de ojos, barba de pelo sintético y cuerpo recubierto de hilos de color dorado amarillento. Una figura que, a pesar de mantener la iconografía característica de la figura de Daruma, se vende únicamente como souvenir y ha perdido todo el trasfondo simbólico que tradicionalmente habían tenido.

Esta curiosa figura de Daruma hace pareja con una figura femenina conocida como Hime Daruma (SM n $\left.{ }^{\circ} 68\right) .{ }^{58}$ Una recreación de una de las representaciones típicas de la tradición y la cultura popular, en las que Daruma aparece representado como una figura femenina, que solían llamarse Onna Daruma (mujer Daruma) o Hime Daruma (princesa Daruma).

La Hime Daruma, era considerada un amuleto o engimono que proporcionaba buena salud, ${ }^{59}$ ya que había la creencia de que si la acariciaban los niños, estos crecían de forma saludable, y si se colocaba en el cojín de un enfermo, ayudaba a que se recuperase. Las típicas y originales eran de papel maché, pero debido a la gran popularidad de estas figuras, se empezaron a elaborar con todo tipo de materiales (brocados, hilos de seda, cabellos adheridos, etc.) y se venden como souvenir, perdiendo el simbolismo que tradicionalmente habían tenido. Y esta figura es un curioso ejemplo: mantienen la característica forma de tentetieso -con un cuerpo globular de color rojizo- pero con una decoración particular (cuentas plateadas e hilo de terciopelo) y un rostro realizado en base a dos cuentas de color negro a modo de ojos, pestañas pintadas alrededor, y dos puntadas de hilo de color rojo en forma de triángulo invertido a modo de boca.

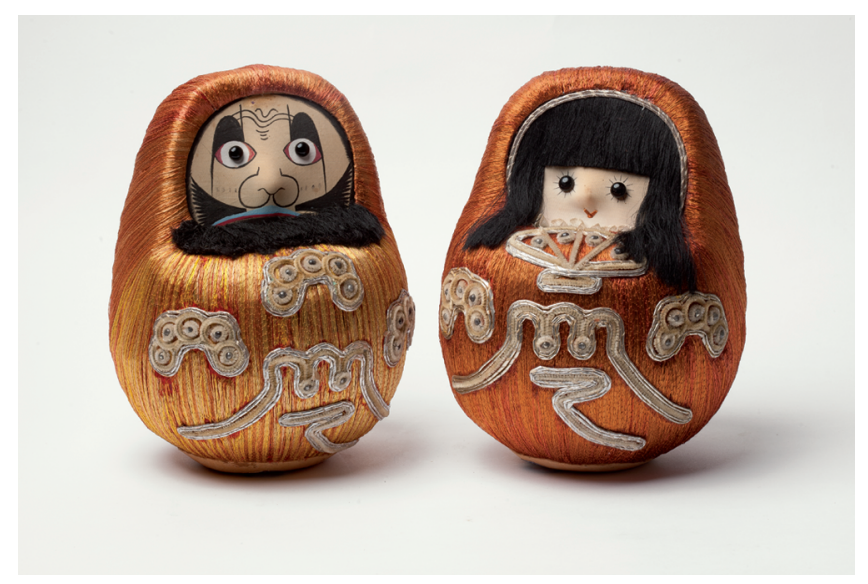

Fig. 6. Daruma (SM no 104) y Onna Daruma (SM no 68), Japón. Fotografía Gabriel Ramon. Archivo Successió Miró. (C) Successió Miró.

Únicamente hemos localizado un ejemplar exactamente igual a esta Hime Daruma en una ilustración del opúsculo The Japanese Doll, de Luella Tilton Hart, publicado en $1952 .{ }^{60}$

Miró también contaba entre su colección con otro engimono conocido, una miniatura de izumekoningyo (いづめこ) (SM no 121), ${ }^{61}$ consistente en un muñeco japonés en el interior de una bellota. Figura de la máxima simplicidad: rostro de tela con tres puntos pintados en negro a modo de estilizados rasgos físicos y cuerpo de tela brocada en rojo y dorado.

En la cultura popular y tradicional japonesa se creía que las izumeko-ningyo eran unos amuletos u objetos portadores de suerte que ayudaba a conseguir una feliz vida familiar y muchos hijos. ${ }^{62}$ Hay diferentes versiones de esta figura, de las más sofisticadas (realizadas con ropa y paja) a las más sencillas y básicas (realizadas en arcilla u otros materiales sencillos), pero todas ellas tienen en común que muestran la forma en que en el norte de Japón las familias campesinas transportaban a sus bebés: los campesinos llevaba a sus hijos con ellos mientras trabajaban dentro de cestos y cubiertos de ropa. En invierno utilizaban este mismo sistema

\footnotetext{
${ }^{58}$ Medidas, 23,5 × $17 \times 17 \mathrm{~cm}$. La figura conserva en su base unas etiquetas originales: "Tienda de Minematsu Yamada" y $\mathrm{n}^{\circ}$ registro 49751. Esta figura fue restaurada en 2015.

59 NISIZAWA, T., 1939, p. 41.

60 TILTON HART, L., 1952, p. 39.

${ }^{61}$ Medidas $2 \times 1,5 \times 1,5 \mathrm{~cm}$.

62 BATEN, L., 2000, p. 41.
} 
para mantener a los niños abrigados y calientes mientras estaban en casa. Este tipo de cuna-cesta, utilizada antiguamente en zonas agrícolas, se conoce como izumeko y originalmente era una gran cesta circular de paja utilizada para conservar el arroz cocido caliente.

Un ejemplar curioso es una pequeña figura antropomorfa masculina, que representa a un niño de pie (SM $n^{\circ}$ 57). Lleva una indumentaria típica infantil: haragake (una especie de delantal que cubría la parte delantera del cuerpo, hasta debajo de la cintura), un chaleco y sombrero, los rasgos faciales están pintados en negro y los labios, entreabiertos, en rojo, y aún conserva restos de pelo. Parece ser una tosca copia de unas sofisticadas figuras conocidas como Gosho-ningyô, un tipo de muñecos creados siguiendo la imagen de niños pequeños. ${ }^{63}$ Los Gosho-ningyô se caracterizan por tener una gran cabeza, cuerpo redondeado y una "piel" de un blanco brillante que se consigue con la aplicación de diversas capas de gofun (una pasta de color blanco hecha del polvo de conchas trituradas -carbonato cálcico- mezcladas con una base de goma de procedencia animal) con el que se conseguía una superficie brillante, suave y de efecto porcelanoso. ${ }^{64}$ Solían ir desnudos o vestir haragake, y en ocasiones llevaban también sombrero y chaleco. Y, como regla general, los muñecos originales median entre $10-30 \mathrm{~cm}$, mientras que este es de menor tamaño $(7,5 \mathrm{~cm})$.

Este tipo de figuras se originaron en la corte de Kioto, como regalos para el emperador. Posteriormente continuaron siendo de uso exclusivo para los nobles, como una representación de todo aquello que deseaban para sus hijos: vitalidad, salud, etc. Por ello la práctica totalidad son figuras masculinas. Con el paso del tiempo estas figuras se fueron popularizando, y acabaron vendiéndose como souvenirs. Ello llevó a una simplificación de los materiales utilizados, pasando de los aristocráticos originales en madera de paulonia a la pasta del serrín, la arcilla o papel mache como base sobre la cual aplicar las capas de gofun.
Por último, hacer referencia a los ejemplares de cometas japonesas que Miró atesoraba, en concreto del tipo mukade-dako, 百足凧 o "cometas ciempiés" (SM n²2), ${ }^{65}$ un tipo de cometa articulada que representa a un mukade o ciempiés gigante. Están formadas por numerosas secciones circulares de papel y bambú (10 en este caso), conectadas entre sí por cuerda de cáñamo, que al ser movidas por el viento dan la sensación de un animal reptando. Esta cometa estuvo presente en la biblioteca particular del artista durante años, y hay otro ejemplar que se conserva en la Fundació Pilar i Joan Miró de Mallorca.

Y no podemos obviar en este estudio una representación del takarabune (宝船) con los Sichifukujin (七福神) 66 $^{\circ}$ "Siete Dioses de la Buena Suerte", aunque por el material utilizado (marfil) no podemos considerarlo como kyôdo-gangu, creemos oportuno incluirlo ya que es una de las iconografías más conocidas y populares también entre los kyôdo-gangu. Consiste en la representación de un mítico barco cargado de tesoros (takarabune) que atraca en los puertos el tercer día de año nuevo, llevando toda clase de elementos preciosos, básicamente fardos de arroz, símbolo de riqueza y prosperidad. ${ }^{67}$ La vela del barco muestra los caracteres de takara, tesoro. Este barco lo pilotaban los Sichifukujin (七福神) o siete dioses de la buena suerte, ${ }^{68}$ unas de las divinidades populares mas extendidas y representadas en el Japón tradicional. En este popular grupo se mezclan caracteres del shintoismo japonés, del taoísmo chino y del budismo. Normalmente estos siete dioses son: Jurojin (patrón de la inteligencia), Fukurokuju (dios de la longevidad), Daikoku y Ebisu (dioses de la prosperidad), Hotei (dios de la felicidad), Benzaiten (patrona de la música y el arte) y por último Bishamon (patrón de los guerreros). Representaciones de estos dioses que encarnan la prosperidad y longevidad las hay muy diversas, tanto en grupo como por separado, siendo la mas popular aquella en la que las siete divinidades van en un barco. Segun la tradicion popular, si una imagen de estos

${ }^{63}$ Para información detallada sobre estas figuras véase PATE, A.S., 2005, pp. 16-79; PATE, A.S., 2008.

${ }^{64}$ Presenta suciedad, adherencias y pérdida de gofun en ciertas partes, pero puede observarse como era originalmente en la parte de la cabeza protegida por el sombrero.

${ }^{65}$ Medidas $26,5 \times 81 \times 180 \mathrm{~cm}$. (desplegada).

${ }^{66}$ Este conjunto actualmente se encuentra dividido: las siete figuras de los dioses de la buena suerte se encuentra en los fondos de la Successió Miró ( $\left.n^{\circ} 116\right)$, mientras que el barco está en la colección particular de la familia.

${ }^{67}$ BATEN, L., 1992, p. 28.

68 Para una información detallada de cada uno de ellos véase MOES, R. (ed.), 1995, p. 36, así como los diccionarios de JOLY, H., 1979 [1967] y BAIRD, M., 2001. 
siete dioses se coloca bajo el cojín la noche del 1 al 2 de enero, con toda seguridad el primer sueño del año sera afortunado.

\section{Conclusiones}

Hemos trazado la biografía de cada uno de estos particulares kyôdo-gangu, y analizado con detalle cómo, con el tiempo, fueron cambiando de usos y significados: cómo pasaron de ser objetos portadores de buena suerte y esperanza dentro de un complejo entramado simbólico a devenir souvenires y/o objetos de coleccionismo.

Se ha detallado y documentado la procedencia de alguno de estos objetos. Hemos confirmado cómo una de las figuras que pertenecen a la colección privada de Miró, concretamente la kokeshi, fue un regalo de Cels Gomis en la década de 1950. Pero no hay constancia documental de que el resto de kyôdo-gangu, también lo fueran, aunque en ocasiones se ha considerado así. ${ }^{69}$ En concreto hemos podido verificar, gracias a las fotografías de su taller en Mallorca realizadas en 1960-1961 por Joaquim Gomis, que en esa época aún no se exhibían en la estantería de la entrada al estudio, por lo cual parece lógico afirmar que por esa época aún no obraban en su poder. Este aspecto parece corroborarlo el hecho que uno de ellos, la representación de uno de los doce animales del zodiaco, sea un gallo y precisamente 1969, el año del segundo viaje a Japón de Miró, fue un año del gaIlo. También hemos documentado la procedencia de otra de las figuras, en concreto la de Jizô-sama ya que, gracias a las inscripciones en una estela de madera que acompañaba a la figura en piedra policromada y la documentación gráfica, hemos podido confirmar que fue un regalo del escultor Takagi Tatsuo en septiembre de 1966, año del primer viaje de Miró a Japón. Por tanto, y con excepción hecha de la kokeshi regalo de Cels Gomis, el resto de kyôdo-gangu podemos concluir que llegaron a manos de Joan Miró bien durante sus viajes a Japón o bien con posterioridad (regalos posiblemente de familiares y/o amigos).

No hay constancia sobre si Miró realmente sabía el significado de todos estos objetos, o si le interesaban únicamente desde un punto de vista formal y estético, más por ser objetos de gran sencillez y conectados con el mundo tradicional y la cultura popular. Pero sí conocemos de su temprano interés por ellos. Tal y como hemos visto, gracias a las fotografías de Joaquim Gomis y a las crónicas periodísticas del momento, sabemos que Miró visitó la exposición que unos recién llegados Eudald Serra y Cels Gomis organizaron en 1950 en el Reial Cercle Artístic de Barcelona, en la cual había una amplia selección de juguetes populares japoneses, entre los que destacaban 17 kokeshi $^{70} \mathrm{Y}$ de las kokeshi, por ejemplo, se explicaba que eran "muñecas populares del noroeste del Japón. También lo usan como amuleto las mujeres casadas para tener hijos". ${ }^{71}$ Por lo tanto, hemos podido corroborar que, como mínimo de algunos de ellos, como es el caso de la kokeshi, sí conocía su significado simbólico.

El que Joan Miró conservara y conviviera con estos kyôdo-gangu es una muestra más que refleja su sensibilidad y admiración por el arte popular, fuese cual fuese su procedencia.

\section{Bibliografía}

APPADURAl, A. (ed.). The Social Life of Things. Commodities in Cultural Perspective. Cambridge: Cambridge University Press, 1986.

BAIRD, M. Symbols of Japan. Thematic motifs in Art and Design. Hong Kong: Rizzoli Int. Publications, 2001.

BATEN, L. Japanese Dolls. The image and the motif. Tokyo: Shufunotomo, 1990.

BATEN, L. Japanese Folk Toys. The Playful Arts. Tokyo: Shufunotomo, 1992.

BATEN, L. Identifying Japanese Dolls. Notes on ningyo. Leiden: Hotei Publishing, 2000.

BRU, R. "En torno al movimiento mingei. Cels Gomis y el coleccionismo de arte popular japonés". Goya: Revista de arte, 2017, $\mathrm{n}^{\circ} 359$, pp. 164-181.

CABAÑAS, P. La fuerza de Oriente en la obra de Joan Miró. Madrid: Electa, 2000.

EVANS, M.; WOLF, R.. Kokeshi. California: Vermillion Publishing, 2005.

FUNK, S. "Northern Japan Traditional Kokeshi". Ningyo Journal, Winter 2003. En: https://www.lasieexotique. com/page/LasieExotique-mag_kokeshi.html (fecha de consulta: 9 enero 2019).

"Japón en la Plaza Catalunya", Destino, n 664, 29 abril 1950, p. 7.

GÓMEZ PRADAS, M. El movimiento Mingei en las colecciones del Museu Etnològic de Barcelona. El caso de los kyôdo-gangu o juguetes populares y tradicionales japoneses. Tesis doctoral, 2011. En: http://zaguan.unizar.es/record/6541/files/TESIS-2011-068.pdf, ISBN: 97884-694-9900-9.

GÓMEZ PRADAS. M. “Los juguetes populares y tradicionales y la construcción de género en la sociedad japo-

\footnotetext{
${ }^{69}$ Véase el artículo de BRU, R. 2017, p. 178, nota 64.

70 En concreto, gracias al folleto-catálogo de la exposición sabemos que se expusieron 43 juguetes, concretamente 17 kokeshi, 12 caballos, 6 tigres, 1 cabeza de león, 1 gato, 3 peces, 2 mujeres y un amuleto. LLOPIS, A., 1950, p. 6.

71 LLOPIS, A., 1950, p. 6.
} 
nesa". Kokoro (monográfico: Japón: identidad, identidades), 2013, pp. 1-19.

GÓMEZ PRADAS, M. "Traçant universos femenins amb paper maixé: la tradició de Takamatsu-hariko en les col-leccions del Museu Etnològic de Barcelona". Dighitum, 2015, pp. 36-43.

GRIBBIN, J. \& D. Japanese Antique Dolls. New York, Tokyo: Weatherhill, 1984

JEFFET, W. "Miró i l'objecte". En JEFFET, W. Miró i I'objecte. Barcelona: Fundació Joan Miró, 2015, pp. 15-35.

JOLY, H., Legend in Japanese Art. Tokyo: Charles E. Tuttle, 1979 [1967].

KAWAGOE, A. "Beyond Textual Approaches in Japanese Folk Art Studies". Trabajo inédito para el 49th Annual Meeting of Association for Asian Studies, Michigan University, marzo de 1997, s/p.

KAWAKAMI, S. Ningyô: The art of the human figurine. New York: Japan Society, 1995.

LLOPIS, A. Exposición de arte popular japonés. Barcelona: Cobalto 49, 1950.

MATSUDA, K. "La primera estancia de Miró en Japón y su contexto histórico". En: M. CABAÑAS, M.; RINCÓN, W. (ed.), El arte y la recuperación del pasado reciente. Madrid: Consejo Superior de Investigaciones científicas, 2015, pp. 362-371.

MCFARLAND, H. N. Daruma. The Founder of Zen in Japanese Art and Popular Culture. Tokyo: Kodansha Int.,1987.
MOES, R. (ed.). Mingei. Japanese Folk Art from the Montgomery Collection. Virginia: Art Services International, 1995.

NISIZAWA, T. Japanese Folk Toys. Tokyo: Tourist Library, $1939, \mathrm{n}^{\circ} 26$.

PATE, A.S. "Gosho-ningyô: Palace Dolls and Auspicious Wishes". En: SCOTT PATE, A. Ningyô. The Art of Japanese Dolls. Singapore: Tuttle Publishing, 2005, pp. 1679

PATE, A.S. "Big, Fat, Round, Large Goshô Ningyo: Palace Dolls of Japan". Antique Doll Collector, June, 2008, vol. 11, n 5. En: http://www.antiquejapanesedolls.com/ pub_gosho/gosho_ningyo.html (fecha de consulta: 9 enero 2019).

PATE, A.S. Japanese Dolls. The Fascinating World of Ningyo. Singapore: Tuttle Publishing, 2008.

SEKOSO, T. (ed.). Japanese Games and Toys. Tokyo: Hitachi, 1973.

SHISHIDO. The Folk Toys of Japan. Tokyo: Japan Publications Trading Co.,1963.

TAKEUCHI, C. An invitation to Kokeshi Dolls. Tokyo: Tsugaru Shobo, 1982.

TILTON HART, L. The Japanese Doll. s/e, 1952.

YANAGI, S. El arte popular japonés. Tokyo: Kokusai Bunka Shinkokai, 1939.

YANAGI, S. The Unknown Craftsman. Tokyo: Kodansha Int., 1989 [1972] 